\title{
Mujer, exclusión social y renta activa de inserción. Especial referencia a la protección de las víctimas de violencia de género
}

\author{
Josep Moreno Gené, Ana M. ${ }^{a}$ Romero Burillo \\ Universitat de Lleida \\ jmoreno@dpub.udl.cat; aromero@dpub.udl.cat
}

\section{Resumen:}

En este estudio se aborda la protección que recibe la mujer ante situaciones de pobreza y exclusión social en la renta activa de inserción, con la finalidad de analizar si el tratamiento dispensado es el adecuado o si, por el contrario, ante la insuficiencia de la protección recibida, debe procederse a un replanteamiento de esta prestación. Para ello, se analiza tanto el tratamiento que con carácter general se prevé para la mujer en la renta activa de inserción como la regulación contenida en ella especificamente para el supuesto de las mujeres víctimas de violencia de género.

Palabras clave: mujer, pobreza, exclusión social, renta activa de inserción, empleo, violencia de género.

\footnotetext{
Abstract

This study deals with the protection afforded to women against poverty and social exclusion by the benefit payment known as the renta activa de insercion. It aims to analyze whether the measure is sufficient and, if it is not, whether it needs to be rethought. To this end, both the general provisions envisaged for women by the renta activa de insercion and the specific regulations for those cases of women who are victims of gender violence are analyzed.

Key words: woman, poverty, social exclusion, renta activa de inserción (a Spanish benefit payment), employment, gender violence.
} 


\section{El papel de las rentas de inserción en el actual sistema de protección social}

El constante incremento del desempleo y la precariedad laboral —bajos salarios, eventualidad, etc.—, junto con la progresiva disminución del ámbito de la protección dispensada por la Seguridad Social —endurecimiento de los requisitos para acceder, reducción de la calidad de las prestaciones, limitación temporal de las mismas-, ha comportado la generalización de los fenómenos de pobreza y de exclusión social. En otros términos, la situación socioeconómica actual, caracterizada por elevadas tasas de desempleo estructural — masivo y de larga duración—, acompañada de la insuficiencia de los sistemas de protección social tradicional, han generado intensos procesos de «dualización» y exclusiones sociales ${ }^{1}$. En este sentido, se han apuntado tres elementos que han provocado o agravado estos procesos de exclusión social: el cambio de orientación de la acción del Estado, la degradación y devaluación del trabajo para amplias capas de ocupados y el crecimiento del desempleo y de las nuevas desigualdades sociales y económicas ${ }^{2}$; no en vano, el trabajo asalariado y los sistemas de protección social, con el complemento de la familia - la estructura tradicional, la cual también ha mutado-, han sido hasta la actualidad los principales elementos de integración social ${ }^{3}$.

Dentro de estos procesos de exclusión social de importantes capas de la sociedad se pueden distinguir, sin embargo, diversos estratos: un primer grupo estaría formado por trabajadores precarios, que entran y salen periódicamente del mercado de trabajo, accediendo o no según las circunstancias a la correspondiente protección dispensada por la Seguridad Social. Estos trabajadores se encuentran en riesgo de caer en situaciones próximas a la pobreza o exclusión social, según el tiempo que se prolongue esta situación y la protección que reciban de la Seguridad Social. Un segundo grupo comprende aquellos colectivos que no han participado o, en su caso, han participado de forma marginal en el mercado de trabajo - trabajo sumergido, autoempleo, tra-

1 Monereo Pérez, J. L. y Molina Navarrete, C. «Un nuevo derecho social de ciudadanía: modelos normativos de "rentas mínimas de inserción" en España y en Europa». Revista de Trabajo y Seguridad Social. CEF, n 187/1998, pág. 79. Rodríguez Cabero, G. «Integración, asistencialización y exclusión en el Estado de Bienestar», en Albarracín, J. et alii (comp.): La larga noche neoliberal. Políticas económicas de los ochenta. Ed. Icaria-ISE. Barcelona-Madrid, 1993.

2 Santos Ortega, A.; Montalbà Ocaña, C. y Moldes Farelo, R. Paro, Exclusión y Políticas de Empleo. Aspectos sociológicos. Ed. Tirant lo Blanch. Valencia, 2004, pág. 275. Véase también Estévez González, C. Las Rentas Mínimas Autonómicas. Estudio de las normativas reguladoras y análisis jurídico de las prestaciones. Ed. CES. Madrid, 1998, págs. 30 a 35.

3 Moreno Domínguez, M. La protección pública no contributiva frente a la exclusión social. Análisis jurídico-económico. Ed. CARL. Sevilla, 2004, págs. 34 y 35. En esta misma dirección, Rojo Torrecilla, E. «Protección social y rentas mínimas de inserción. De la cobertura económica al derecho de ciudadanía», en López López, J. (coord.): Seguridad Social y Protección Social: temas de actualidad. Ed. Marcial Pons. Madrid, 1996, págs. 99 a 102, pone de manifiesto los cambios socioeconómicos y políticos operados a partir de los inicios de los años setenta del pasado siglo: envejecimiento de la población, transformación progresiva de las estructuras familiares y aumento de las familias monoparentales, persistencia de un nivel de desempleo elevado y de larga duración y aparición y desarrollo de nuevas formas de marginación y pobreza. 
bajo doméstico, etc. - y, en consecuencia, no han accedido tampoco a la protección dispensada por la Seguridad Social. Este colectivo ya se encuentra en una situación real de pobreza y exclusión social, que lo aleja no únicamente del mercado laboral, sino también del conjunto de la sociedad, pudiendo derivar fácilmente en situaciones más marginales de alcoholismo, drogodependencia, indigencia, delincuencia, etc. (situaciones de marginación social) ${ }^{4}$.

Estos colectivos, a pesar de sus diferencias, comparten el ser los representantes de lo que se ha denominado como una nueva forma de pobreza, frente a la pobreza tradicional, y que comprende, entre otros grupos, a los hogares encabezados por mujeres, los grupos más jóvenes (hasta 29 años de edad), los desempleados de larga duración, las personas analfabetas o con un nivel bajo de estudios, los emigrantes, etc. Como fácilmente puede observarse, la mujer ocupa un lugar preponderante en cada una de las situaciones expuestas anteriormente conducentes a la situación de exclusión social, al encabezar la mayor parte de los hogares monoparentales, por ser uno de los colectivos con mayores dificultades de inserción en el mercado laboral, por liderar los índices de desempleo de larga duración, por representar en algunas franjas de edad la mayor parte de personas analfabetas o con un nivel bajo de estudios, por constituir una parte importante del colectivo de inmigrantes, etc.

Frente a estas nuevas formas de exclusión social, la Seguridad Social tradicional se ha mostrado un tanto inoperante; no en vano, si atendemos a su nivel contributivo, los requisitos de acceso a la protección continúan siendo contributivos, excluyentes, por tanto, de determinados sectores que, como se ha puesto de manifiesto, no se han incorporado al mercado de trabajo o, en su caso, lo han hecho de una forma muy irregular ${ }^{5}$. En otros términos, dado que el nivel contributivo se basa en la previa cotización que genera el derecho a una prestación, la protección queda vinculada a la previa participación en el mercado de trabajo, tanto por lo que hace referencia al derecho a ella como a su intensidad y duración. En consecuencia, estando en crisis los supuestos en que se apoya la protección social para el nivel contributivo de la Seguridad Social, es decir, un trabajo más o menos estable, ésta pasa a reproducir las previas desigualdades y exclusiones del mercado de trabajo del cual depende. Por tanto, la protección social basada en el principio contributivo reproduce las exclusiones y no sirve para evitar la pobreza $^{6}$.

4 Standing, G. «El camino hacia el subsidio activo. ¿Otra forma de protección social o amenaza para la ocupación?», en Revista Internacional del Trabajo, vol. 109, n. ${ }^{\circ} 4 / 1999$, págs. 499 y 500.

5 Sobre las deficiencias e incapacidad de la protección dispensada por el sistema de la Seguridad Social para combatir la pobreza y la exclusión social véase Estévez González, B. Las Rentas Mínimas..., op. cit., pág. 51, y Monereo Pérez, J. L. y Molina Navarrete, C. «Un nuevo derecho social de la ciudadanía: modelos normativos de rentas mínimas de inserción en España y en Europa». Revista de Trabajo y Seguridad Social. CEF, n. ${ }^{\circ}$ 187/1998, pág. 79.

6 Noguera, J. A. «La renta básica y el principio contributivo», en Raventós, D. (coord.): La Renta Básica. Por una ciudadanía más libre, más igualitaria y más fraterna. Ed. Ariel. Barcelona, 2001, págs. 71 y 72. 
Ante la constatación de las dificultades de este nivel contributivo de la Seguridad Social a la hora de abarcar la problemática suscitada por las nuevas formas de pobreza y de exclusión social, se produjo una reacción para intentar proteger a colectivos en situación de necesidad anteriormente huérfanos de protección. En este sentido, se previó una pensión no contributiva de jubilación, una de invalidez y una de prestación por hijo a cargo, las cuales se van a sumar a los complementos a mínimos de las pensiones contributivas y al nivel asistencial de la protección por desempleo. Ahora bien, a pesar de esta ampliación del ámbito de la protección de la Seguridad Social, todavía quedaban fuera del mismo aquellas personas entre 18 y 65 años con capacidad para trabajar o, en todo caso, con una discapacidad inferior a la exigida para acceder a la pensión no contributiva de invalidez, las cuales, en la medida en que no se hubieran incorporado al mercado de trabajo o lo hubieran hecho de forma insuficiente, no podrían acceder a las prestaciones contributivas o, en su caso, habiéndolo hecho, ya las habrían agotado, ni tampoco podrían acceder al nivel no contributivo ${ }^{7}$. Es éste el vacío que era necesario cubrir, y que finalmente ha sido cubierto, aunque solamente de forma parcial, por las rentas de inserción, ya sea la renta activa de inserción estatal o las rentas mínimas autonómicas ${ }^{8}$.

Partiendo de las anteriores ideas, está claro que las rentas de inserción ayudan al ciudadano excluido a disfrutar de los derechos que por su situación de extrema pobreza lo tenían al margen de la vida en sociedad (y prácticamente del estatus de ciudadano) y de los derechos básicos de toda persona, como son el derecho a la cultura, al trabajo, a la salud, a una vida digna y a la educación. Como también ayudan al ciudadano en situación económica de precariedad a superarla y a eludir el riesgo de exclusión social. Por ello, es evidente que si el reto del actual Estado social es conseguir trabajo para los que no lo tienen ${ }^{9}$, como premisa para obtener los medios de vida y acceder a las oportunidades disponibles para los ciudadanos ${ }^{10}$, las rentas de inserción son un instrumento más de ayuda en la consecución de este reto. Con el fin de hacer frente a

7 Para un estudio sobre el espacio de desprotección del sistema de Seguridad Social contributivo y asistencial que se pretende cubrir con la renta mínima de inserción véase García Romero, M. B. Rentas Mínimas Garantizadas en la Unión Europea. Ed. CES. Madrid, 1999, págs. 139 a 176.

8 En este punto, el Consejo de Estado indica que «el trazado de fronteras entre la Seguridad Social estatal, descrita tan ampliamente en el artículo 41 de la Constitución, y otras formas de protección social, de competencia autonómica, tiene un criterio delimitador de carácter negativo, en el sentido de que los espacios de asistencia social son, ante todo, espacios 'vacíos' de protección de la Seguridad Social e incluye a personas en situaciones de riesgo o necesidad que el sistema público de Seguridad Social no cubre o no cubre suficientemente. En este sentido, existe una frontera móvil, que depende de la decisión del Estado, en función de sus medios y posibilidades y opciones políticas, de ampliar la esfera de sujetos y objetos protegidos por el sistema público de Seguridad Social». Véase Consejo de Estado: Dictamen al proyecto de Real Decreto por el que se regula el programa de renta activa de inserción para desempleados con especiales necesidades económicas $y$ dificultad para encontrar empleo, de 11 de octubre de 2006.

9 De esta forma, el factor trabajo recupera su función en la escala de valores y la inserción se plantea como imperativo para resolver los problemas derivados de la exclusión. Así lo indica Mercader Uguina, J. R. Derecho del trabajo, nuevas tecnologías y sociedad de la información. Ed. Lex Nova. Valladolid, 2002, págs. 281 a 283.

10 Rodríguez-Piñero, M. «Empleo y exclusión social», en Relaciones Laborales, vol. I/2002, pág. 124. 
esta situación y, por tanto, para proteger a estos colectivos, se han desarrollado, a escala estatal y autonómica, diversos programas que, desde perspectivas diversas — desde la Seguridad Social las primeras, y desde la Asistencia Social las segundas-, intentan dar respuesta a estas «nuevas necesidades». Nos referimos, fundamentalmente, a la renta activa de inserción y a las rentas mínimas autonómicas ${ }^{11}$.

En este contexto, se ha aprobado el Real Decreto 1369/2006, de 24 de noviembre, por el que se regula el programa de renta activa de inserción para desempleados con especiales necesidades económicas y dificultades para encontrar empleo, que, a diferencia de lo sucedido hasta la aprobación de esta norma, no configura a esta prestación como un programa de duración anual, sino que la ordena con carácter permanente, estableciéndose una garantía de continuidad en su aplicación como un derecho más y con la misma financiación que el resto de las prestaciones y subsidios por desempleo. Esta norma define la renta activa de inserción con las siguientes notas $; a$ ) se concede una renta activa de inserción a los desempleados que acepten el compromiso de actividad en virtud del cual manifiesten su plena disponibilidad para buscar efectivamente empleo, para trabajar y para participar en las acciones ofertadas por los servicios públicos de empleo y dirigidos a favorecer su inserción laboral; y $b$ ) a partir de este compromiso, se aplican diferentes políticas de empleo activas y pasivas a los diferentes colectivos a los que se dirige el programa de desempleados en situación de necesidad y con menores posibilidades de ocupación: por ser mayores de 45 años, desempleados de larga duración o emigrantes retornados, o por ser desempleados de cualquier edad, discapacitados o víctimas de violencia de género o doméstica, siempre que, en cada caso, se reúnan los requisitos exigidos para ser beneficiarios del programa.

A pesar de las mejoras que se han ido introduciendo, se constata que la renta activa de inserción todavía es insuficiente, tanto desde un punto de vista cuantitativo como cualitativo. Así, por ejemplo, no sólo son limitados los posibles beneficiarios, sino que ni siquiera todos aquellos posibles beneficiarios acceden a la protección dispensada por la renta activa de inserción, lo que deja fuera de su ámbito de protección a importantes colectivos, especialmente el de los jóvenes desempleados o mujeres con difícil acceso al mercado de trabajo. Este hecho se ve agravado por las deficiencias burocráticas, así como por su excesiva homogeneización, que impide adaptarla a las peculiaridades de los diversos colectivos protegidos por la renta activa de inserción. A estas deficiencias debe añadirse el escaso éxito de las medidas derivadas del compromiso de actividad que se impone al beneficiario.

Como consecuencia de estas y otras deficiencias detectadas en la renta activa de inserción, se ha puesto de manifiesto ya con anterioridad a la aprobación del R. D.

11 Sobre el papel de las rentas de inserción en el sistema de protección social véase Purcalla Bonilla, M. A.; Moreno Gené, J.; Romero Burillo, A. M. y Urquizu Cavallé, A. La renda minima de inserció catalana en el sistema de protecció social. Ed. Institut d'Estudis Autonòmics. Generalitat de Catalunya. Barcelona, 2006. 
1369/2006, de 24 de noviembre, la necesidad de otros sistemas se protección que, ante el cambio del perfil de pobreza y de exclusión social, otorguen la debida protección a aquellas personas que, aunque encontrándose en edad de trabajar, han quedado al margen del sistema de protección social. Entre estos sistemas destacan especialmente las rentas mínimas de inserción que progresivamente se han instaurado en toda Europa, y posteriormente en España, con la particularidad de que las mismas han sido previstas y reguladas no por el Estado, sino por las diferentes comunidades autónomas, lo que plantea indiscutibles cuestiones no sólo en materia de distribución de competencias, sino también en relación a cómo deben articularse y/o complementarse los diversos sistemas de protección previstos por el Estado - Seguridad Social - y por las comunidades autónomas - Asistencia Social- ${ }^{12}$.

Las rentas mínimas se encuentran en un proceso de universalización subjetiva, si bien hay que afirmar que este es un objetivo todavía no conseguido. En consecuencia, la renta mínima de inserción todavía se limita a una protección dirigida a aquellos individuos y sus familias que se encuentran en una situación de pobreza extrema, que se caracteriza por la marginación que comporta, lo que excluye a muchos hogares de la protección dispensada por la misma. Es decir, no se trata de una red universal que cubra a todo el mundo que no tenga acceso al sistema contributivo o no contributivo de cobertura de las situaciones de pobreza. Todo esto nos permite poner de manifiesto el carácter excesivamente limitado que todavía tienen las rentas mínimas de inserción autonómicas, así como la necesidad de profundizar en su universalización o generalización, ya sea ampliando progresivamente los sujetos/colectivos protegidos, para intentar abarcar todas aquellas situaciones de pobreza y exclusión social necesitadas de protección, ya sea sustituyendo la renta mínima de inserción por otros mecanismos de protección propuestos, como la renta básica de ciudadanía y/o la renta universal.

En este estudio se aborda el tratamiento que recibe la mujer en el primero de los sistemas de protección social expuestos, es decir, la renta activa de inserción, con la finalidad de analizar si la protección que recibe es la adecuada o si, por el contrario, ante la insuficiencia de dicha protección debe procederse a un replanteamiento de la misma. Para ello analizaremos, en primer lugar, el tratamiento que con carácter general recibe la mujer en la renta activa de inserción, para pasar a abordar, posteriormente, la regulación prevista en la misma para el supuesto específico de las mujeres víctimas de violencia de género.

12 Sobre esta cuestión, véase Purcalla Bonilla, M. A.; Moreno Gené, J.; Romero Burillo, A. M. y Urquizu Cavallé, A. La renda mínima de inserció..., op. cit. 


\section{La mujer como destinatario específico de la renta activa de inserción: su falta de visibilidad}

En el marco de la renta activa de inserción, y como sucede con otras prestaciones, el acceso a ella está condicionado por el cumplimiento de determinados requisitos, los cuales sin duda se encuentran vinculados a la finalidad dual de esta prestación, es decir, garantizar unos ingresos mínimos y procurar la inserción laboral de sus beneficiarios. A partir de estas premisas se pueden distinguir, en primer lugar, los requisitos subjetivos, es decir, la identificación de aquellos colectivos beneficiarios de esta prestación (art. 2 R. D. 1369/2006, de 24 de noviembre) y, en segundo lugar, el elemento objetivo necesario para acceder a la renta activa de inserción, que básicamente se identifica con la suscripción de un compromiso de actividad en virtud del cual el beneficiario se obliga a participar en diversas acciones de inserción (art. 3 del R. D. 1369/2006, de 24 de noviembre).

Centrándonos en el aspecto subjetivo de esta prestación, el art. 2.1 del R. D. $1369 / 2006$ establece que podrán ser beneficiarios de ella los desempleados menores de 65 años que, a la fecha de solicitud de incorporación, reúnan los siguientes requisitos: a) ser mayor de 45 años; y b) ser demandante de empleo inscrito, ininterrumpidamente, como desempleado en la oficina de empleo durante 12 o más meses. Así mismo, de acuerdo con lo previsto en el art. 2.2, podrán ser beneficiarios los trabajadores desempleados menores de 65 años que, a la fecha de solicitud, reúnan alguno de los siguientes requisitos: a) acreditar una minusvalía en grado igual o superior al $33 \%$, o tener reconocida una incapacidad que suponga una disminución en su capacidad laboral del porcentaje anteriormente indicado; $b$ ) ser trabajador emigrante que, tras haber retornado del extranjero en los 12 meses anteriores a la solicitud, hubiera trabajado como mínimo seis meses en el extranjero desde su última salida de España, y esté inscrito como demandante de empleo; y c) tener acreditada por la Administración competente la condición de víctima de violencia de género o doméstica, salvo cuando conviva con el agresor, y estar inscrita como demandante de empleo. Finalmente, el art. 2.3 incluye entre los beneficiarios de la renta activa de inserción a los beneficiarios de pensiones de invalidez no contributiva, si reúnen en el momento de la solicitud los requisitos exigidos en el art. 2, excepto el requisito de la falta de rentas, siempre que se acreditara que dejarían de percibirlas, a través de una certificación de la Administración competente sobre la suspensión de la pensión a partir de la fecha en que se iniciara el pago de la renta activa de inserción.

De la exposición realizada puede concluirse que son dos las notas que caracterizan el ámbito subjetivo actual de esta prestación: la heterogeneidad de los colectivos incluidos y su insuficiencia. Por lo que hace referencia a la primera, hay que poner de relieve 
la heterogeneidad de los colectivos que progresivamente se han ido incluyendo en el ámbito de aplicación de la renta activa de inserción, desde su configuración inicial en el año 2000 como un programa de inserción laboral para los trabajadores desempleados de larga duración en situación de necesidad, mayores de 45 años, hasta la configuración actual, que incluye, junto con este colectivo inicialmente protegido, a colectivos tan diversos como son los discapacitados, los emigrantes retornados, las víctimas de violencia de género o doméstica y los beneficiarios de la pensión de invalidez no contributiva que opten por la renta activa de inserción.

Esta heterogeneidad no plantea por sí misma ningún inconveniente, ni ha de resultar contradictoria con las finalidades y objetivos que se persiguen con la renta activa de inserción; no en vano, siendo los destinatarios de este programa los desempleados con especiales necesidades económicas y dificultades para encontrar trabajo, y siendo la finalidad del mismo la reinserción laboral y la protección ante el desempleo, todos los colectivos incluidos actualmente en el ámbito subjetivo de la renta activa de inserción justifican sobradamente su protección a través de esta prestación. En este sentido, se ha puesto de manifiesto que la paulatina ampliación de los colectivos beneficiarios de la renta activa de inserción implica un cierto reconocimiento del carácter multidimensional y relativo del fenómeno de la exclusión social, y de la heterogeneidad de causas que pueden llevar a una situación de exclusión laboral y social ${ }^{13}$. En un tono más crítico también se ha considerado que la coyuntura del ámbito subjetivo de la renta activa de inserción ha funcionado como «amortiguador social» - o «apagafuegos»- de políticas restrictivas en otros ámbitos de la protección social, o de anticipación de líneas nuevas de acción social — violencia de género-, o de complemento de otras que se resisten a ser todo lo eficaces que se pretende — discapacitados - ${ }^{14}$.

Por el contrario, los posibles problemas que se pueden derivar de esta heterogeneidad en el ámbito subjetivo de la renta activa de inserción vienen dados más bien por el tratamiento homogéneo que se puede dar a los diferentes colectivos, ya que, a pesar de que éstos responden básicamente a la misma problemática - especiales necesidades económicas y dificultad para encontrar un trabajo-, la solución no tiene por qué ser igual para todos ellos ${ }^{15}$. En este sentido, en tanto que algunos colectivos únicamente padecen un problema de inserción laboral, otros pueden plantear otros problemas de inserción social que es necesario resolver antes de abordar propiamente la inserción

13 Fernández Avilés, J. A. «El programa de renta activa de inserción para el año 2002 (comentario a la Disposición Adicional Primera del R. D.-Ley 5/2002, de 24 de mayo)». Revista Española de Derecho del Trabajo, n. ${ }^{\circ}$ 114/2002, pág. 901.

14 Molina Navarrete, C. y Vallecino Gámez, M. R. «El “derecho a” y las “políticas de” de inserción a favor de los desempleados más vulnerables: balance del quinquenio de “rentas activas de inserción”». Revista de Trabajo y Seguridad Social. CEF, n. ${ }^{\circ} 268 / 2005$, pág. 18 .

15 Fernández Aviles, J. A. «El programa de renta activa de inserción...», op. cit., pág. 901, alerta precisamente contra la tentación de la uniformidad y la estandarización de las medidas de inserción. 
laboral. Así, puede resultar tan innecesario adoptar algunas medidas de inserción en relación con colectivos que se encuentran perfectamente integrados en la sociedad, como ineficaz abordar la inserción laboral de algún colectivo sin acabar de resolver satisfactoriamente su inserción social. En definitiva, se han de adaptar los programas de renta activa de inserción a las necesidades específicas de los diferentes colectivos que protege.

Más criticable resulta la segunda nota característica del ámbito subjetivo de la renta activa de inserción, es decir, su insuficiencia, que impide considerarla como un instrumento realmente eficaz para afrontar los problemas de la doble exclusión, la social y la ocupacional ${ }^{16}$. En este sentido, a pesar de valorar positivamente la progresiva ampliación del ámbito subjetivo de esta prestación ${ }^{17}$, debe ponerse de manifiesto que todavía se pueden identificar otros colectivos que también responderían a las mismas características reseñadas en relación con los colectivos incluidos, es decir, desempleados con especiales necesidades económicas y dificultades para encontrar trabajo, que como consecuencia de la situación en que se encuentran, tienen un alto riesgo de caer en situaciones de exclusión social y de pobreza. Para estos colectivos también resulta sin duda aplicable el doble objetivo de la renta activa de inserción, es decir, la reinserción laboral y la protección ante el desempleo.

Aunque en ocasiones se ha considerado que una excesiva extensión subjetiva de la renta activa de inserción podría comportar una falta de efectividad, siendo preferible una tutela selectiva a fin de no desvirtuar el sistema o, en otras palabras, sus objetivos de integración laboral, consideramos que el alcance limitado del ámbito subjetivo de la renta activa de inserción pone claramente de manifiesto que esta prestación supone un mecanismo limitado de protección y que, por tanto, difícilmente cumple con el objetivo que aparentemente se le asigna como última red de seguridad o garantía frente a aquellas situaciones de desprotección social que vienen originadas por la falta de un trabajo remunerado ${ }^{18}$.

Entre estos colectivos desprotegidos a los cuales podría extenderse la protección dispensada por la renta activa de inserción destaca con luz propia, además de los jóvenes, los inmigrantes y los ex reclusos, el colectivo de las mujeres. En esta dirección, no cabe duda de que un colectivo que podría incorporarse de forma específica al ámbito subjetivo de la renta activa de inserción es el de las mujeres desempleadas de larga

16 Molina Navarrete, C. y Vallecino Gámez, M. R. «El “derecho a” y las “políticas de” de inserción...», op. cit., pág. 10.

17 En esta dirección, Cavas Martínez, F. «Protección por desempleo e inserción laboral: balance provisional de los programas de renta activa de inserción 2000/2003». Aranzadi Social, Tomo V/2003, pág. 199, valora positivamente la ampliación del ámbito subjetivo a determinadas personas apartadas del mercado de trabajo — por razón de su edad avanzada, minusvalía, retorno del extranjero o violencia de género- - y que, precisamente por ello, pueden caer en la exclusión.

18 En este sentido se manifiesta también Fernández Avilés, J. A. «El programa de renta activa de inserción...», op. cit., pág. 901. 
duración, especialmente cuando hayan abandonado el mercado de trabajo durante un largo período de tiempo para el cuidado de hijos u otras personas dependientes. Las especiales dificultades que, en estos supuestos, puede comportar la reincorporación al mercado de trabajo, justificarían sobradamente su inclusión en el ámbito subjetivo de la renta activa de inserción, especialmente en aquellos casos en que la mujer tiene además responsabilidades familiares. En estos supuestos, puede ser especialmente necesario y eficaz el doble contenido que tiene la renta activa de inserción: la renta económica y las acciones de inserción laboral ${ }^{19}$. En definitiva, la inserción laboral de las mujeres puede ser un objetivo susceptible de protección a través de la renta activa de inserción más allá de los supuestos que más adelante se analizarán, en que las mujeres son víctimas de violencia de género o doméstica ${ }^{20}$.

Ello no significa que, a través de los diferentes colectivos que específicamente se identifican como destinatarios de la renta activa de inserción, no pueda incluirse al colectivo de las mujeres; no en vano, éstas pueden ser desempleadas menores de 65 años que, a la fecha de solicitud de incorporación, reúnan los siguientes requisitos: $a)$ ser mayores de 45 años; $b$ ) ser demandantes de empleo inscritas, ininterrumpidamente como desempleadas, en la oficina de empleo durante 12 o más meses. Así mismo, también pueden incluirse entre los trabajadores desempleados menores de 65 años que, a la fecha de solicitud, reúnan alguno de los siguientes requisitos: a) acreditar una minusvalía en grado igual o superior al $33 \%$, o tener reconocida una incapacidad que suponga una disminución en su capacidad laboral del porcentaje anteriormente indicado; $y$ b) ser trabajador emigrante que, tras haber retornado del extranjero en los 12 meses anteriores a la solicitud, hubiera trabajado como mínimo seis meses en el extranjero desde su última salida de España, y esté inscrito como demandante de empleo. Finalmente, también pueden incluirse en el supuesto específico de los beneficiarios de pensiones de invalidez no contributiva que cumplan determinados requisitos. Todo ello, además de integrar el colectivo de las víctimas de violencia de género o doméstica previsto específicamente por la normativa reguladora de la renta activa de inserción. Sin embargo, consideramos que hubiera sido muy interesante que se hubiera visualizado de un modo mucho más específico al colectivo de las mujeres en la regulación de la renta activa de inserción, al tratarse de un colectivo que puede encontrarse de forma

19 Véase Fernández Avilés, J. A. «El programa de renta activa de inserción...»», op. cit. pág. 904. El autor considera que se tendrían que incluir dentro del ámbito de aplicación de la renta activa de inserción a las mujeres con dificultades para el acceso al mercado de trabajo.

20 De la Casa Quesada, S. y Molina Hermosilla, O. «La renta activa de inserción: una cierta incursión estatal en el ámbito de las políticas de inserción. Comentario al R. D. 781/2001, de 6 de junio». Revista de Trabajo y Seguridad Social. CEF, núm. 224/2001, pág. 138, consideran que debe hacerse especial mención a la inclusión de las mujeres, en tanto en cuanto este colectivo es realmente uno de los que más motivación y acogida ofrecen ante las medidas de acceso al mercado de trabajo, lo que debe tenerse en cuenta por parte de los poderes públicos en futuras ampliaciones del ámbito subjetivo de la renta activa de inserción. 
muy habitual con las especiales necesidades económicas y la dificultad para encontrar empleo que definen a la renta activa de inserción.

En cualquier caso, la no inclusión expresa de estos colectivos, entre los que se encuentran las mujeres, en el ámbito subjetivo de la renta activa de inserción no implica necesariamente su total desprotección, ya que éstos pueden encontrarla a través de otras medidas de protección social previstas en el ordenamiento jurídico, como lo son, por ejemplo, las rentas mínimas de inserción autonómicas. Pese a ello, consideramos recomendable que el primer nivel de protección de estos colectivos y, por tanto, de las mujeres en situación de desempleo, se produzca a través de la renta activa de inserción, es decir, facilitándoles su inserción laboral, antes que tener que recurrir a las rentas mínimas autonómicas, que tendrían que centrarse especialmente en las dificultades de inserción social que no siempre deben estar necesariamente presentes en estos supuestos.

Estas deficiencias del ámbito subjetivo de protección de la renta activa de inserción han desembocado en que se la haya calificado como un parche colocado en el sistema de protección por desempleo que no ha sido capaz de proporcionar la asistencia que precisan todos los desempleados que se encuentran en situación de necesidad económica, ya sea porque han perdido un trabajo o porque aspiran a tenerlo por primera vez. En consecuencia, se ha propuesto una reforma integral del sistema de protección por desempleo que mantenga el nivel contributivo, y al mismo tiempo, contemple una ayuda o prestación genuinamente asistencial a todos los ciudadanos sin trabajo, con capacidad y disponibilidad para trabajar y que se encuentren en una situación de necesidad real por falta de recursos suficientes para subsistir, se denomine ya subsidio de desempleo, ya renta activa de inserción, que combine las prestaciones económicas con acciones para la consecución de un empleo ${ }^{21}$. En otros términos, se considera que la renta activa de inserción debe ser el embrión de una futura renta universal de inserción, que alcance a todos los ciudadanos con capacidad y voluntad de ocupar un puesto de trabajo $^{22}$.

\footnotetext{
21 Véase Cavas Martínez, F. «Protección por desempleo...», op. cit., pág. 200. El mismo criterio es adoptado por Molina Navarrete, C. y Vallecino Gámez, M. R. «El “derecho a” y las “políticas de” de inserción...», op. cit., pág. 36. Estos dos últimos autores mantienen que la renta activa de inserción debe configurarse como la rama no contributiva de la protección por desempleo, de modo que junto al subsidio contributivo aparezca el subsidio no contributivo de desempleo, cualquiera que sea su denominación.

22 Molina Navarrete, C. «Las “rentas activas de inserción”: un viaje inacabado desde la "marginalidad” a la "centralidad” del sistema». Relaciones Laborales, n. ${ }^{\circ}$ 4/2003, pág. 441.
} 


\section{La protección de las mujeres víctimas de violencia de género o doméstica en la renta activa de inserción}

Aunque, como se acaba de poner de manifiesto, la posición desfavorable de la mujer en el mercado de trabajo justificaría plenamente que el colectivo de las mujeres pudiera constituir por sí mismo uno de los colectivos destinatarios de la protección dispensada por la renta activa de inserción, como también ya se ha indicado, ésta no ha sido la opción adoptada por el legislador que, con carácter general, no ha tenido en cuenta las circunstancias de género. Por el contrario, éstas únicamente se han tomado en consideración de una manera indirecta con la inclusión dentro del ámbito subjetivo de la renta activa de inserción de las víctimas de violencia de género o doméstica.

Como afirma el Preámbulo de la Ley Orgánica 1/2004, de 28 de diciembre, de medidas de protección integral contra la violencia de género, éste no es un problema que afecte exclusivamente al ámbito privado, sino que, por el contrario, se manifiesta como el símbolo más brutal de la desigualdad existente en nuestra sociedad. Se trata de una violencia que se dirige sobre las mujeres por el hecho mismo de serlo, por ser consideradas, por sus agresores, faltas de derechos mínimos de libertad, respeto y capacidad de decisión. En consecuencia, los poderes públicos no pueden ser ajenos a la violencia de género, que constituye uno de los ataques más flagrantes a derechos fundamentales como la libertad, la igualdad, la vida, la seguridad y la no discriminación proclamados en la Constitución Española (CE). Estos mismos poderes públicos tienen, de conformidad con lo previsto en el art. 9.2 de la CE, la obligación de adoptar medidas de acción positiva para hacer reales y efectivos estos derechos, eliminando los obstáculos que impiden o dificultan su plenitud.

En este contexto, la condición de víctima de violencia de género o doméstica justifica por sí misma la inclusión de las mujeres que la sufren en el ámbito subjetivo de la renta activa de inserción; no en vano, en la mayoría de supuestos como consecuencia de esta situación, se producirán las especiales necesidades económicas y dificultades para encontrar trabajo que justifican esta prestación, siendo esencial, así mismo, la reinserción laboral y la protección frente al desempleo previstas por esta prestación a favor de este colectivo ${ }^{23}$.

Por todo ello, nos parece interesante conocer cuál es la protección que en estos momentos reciben las víctimas de violencia de género o doméstica en el marco actual de la renta activa de inserción, así como su adecuación a las necesidades que en la práctica puede tener este colectivo de beneficiarios. En todo caso, cabe advertir que, dadas las

23 Serrano Argüeso, M. «Las posibilidades de incorporación al mercado laboral de las víctimas de violencia de género en el ámbito familiar a la luz de las últimas reformas legislativas». Aranzadi Social, n. 20/2004, pág. 67. La autora considera que las mujeres víctimas de violencia doméstica o de género presentan dificultades específicas en el ámbito laboral, de las cuales las normas de Derecho del Trabajo y de la Seguridad Social han de ser conscientes. 
limitaciones de extensión que caracterizan a este tipo de trabajos, únicamente nos detendremos en el análisis de aquellos aspectos de la actual regulación que supongan un tratamiento diferenciado de las víctimas de violencia de género o doméstica respecto al resto de colectivos que pueden ser beneficiarios de la renta activa de inserción, a saber: la delimitación conceptual de víctima de violencia de género o doméstica y el contenido de prestaciones previsto específicamente para este colectivo.

\subsection{Delimitación conceptual de «víctima de violencia de género o doméstica». Del R. D.-Ley 5/2002 al R. D. 1369/2006.}

Con la finalidad de proteger a las víctimas de violencia de género, el R. D.-Ley 5/2002, posteriormente convalidado por la Ley 45/2002, incluyó por primera vez en el ámbito subjetivo de la renta activa de inserción, junto con otros colectivos, a aquellos desempleados que en la fecha de solicitud de incorporación reunieran los siguientes requisitos: tener acreditada por la Administración competente la condición de víctima de violencia doméstica por parte de algún miembro de la unidad familiar de convivencia $y$ estar inscrito como demandante de trabajo, siempre que se reunieran los requisitos exigidos en el apartado 1, excepto el ser mayores de 45 años y estar inscritos como desempleados en la oficina de empleo ininterrumpidamente durante 12 meses o más. A partir de esta previsión, el acceso de este colectivo a la renta activa de inserción se ha mantenido ininterrumpidamente, si bien dicha previsión ha sufrido modificaciones en cuanto a su formulación en los sucesivos programas.

En esta dirección, el R. D. 945/2003, de 18 de julio, prorrogado por el R. D. 3/2004, de 19 de enero, pasó a contemplar como posibles beneficiarios de la renta activa de inserción a aquellas personas que tuvieran acreditada la condición de víctima de violencia doméstica, desapareciendo la anterior previsión de tener que acreditar que la violencia doméstica proviniera de algún miembro de la unidad familiar. Esta redacción solucionaba las cuestiones que podía plantear la inclusión inicial de este colectivo llevada a cabo en el programa para el año 2002, el cual, al establecer expresamente la necesidad de acreditar la condición de víctima de violencia doméstica «por parte de algún miembro de la unidad familiar de convivencia», podía llevar a excluir del ámbito de protección de esta prestación a aquellas víctimas de violencia doméstica ejercida por otros sujetos ajenos a la unidad familiar de convivencia - como, por ejemplo, las ex parejas_- En definitiva, con la redacción introducida en el programa para el año 2003 se contemplaba toda violencia ejercida en el ámbito familiar, hubiera o no convivencia.

Con posterioridad, el R. D. 205/2005, de 25 de febrero, llevó a cabo una nueva modificación de los términos con los que se llevaba a cabo la inclusión de este colectivo, sustituyendo el término «violencia doméstica» por el de «violencia de género». 
La distinción entre violencia doméstica y violencia de género ha sido una constante en los últimos años siempre que se ha abordado esta materia. En este sentido, a pesar de las indicaciones efectuadas por la Real Academia de la Lengua Española, que recomendaba el término de «violencia doméstica», ya la Ley 30/2003, de 13 de octubre, sobre medidas para incorporar la valoración del impacto de género en las disposiciones normativas que elabore el Gobierno, utilizó en lugar del término «sexo», referido a las diferencias físicas entre hombres y mujeres, el de "género», referido a las diferencias sociales asociadas al sexo $^{24}$. De conformidad con esta opción, se ha utilizado mayoritariamente el concepto de violencia de género, siendo la principal manifestación de ello la Ley Orgánica 1/2004, de 28 de diciembre, de medidas de protección integral contra la violencia de género ${ }^{25}$. En esta línea, por tanto, se incardinó también el programa de renta activa de inserción para el año 2005, que, como ya hemos indicado, sustituyó la terminología de violencia doméstica empleada hasta el momento por la de violencia de género ${ }^{26}$.

Este cambio, sin embargo, no se consideró, por algunos autores, como un simple cambio terminológico, sino que ponía de manifiesto que ese cambio podía llevar aparejado también un cambio en su alcance. En este sentido, se consideró que la violencia de género incluía todos los maltratos físicos, psicológicos y económicos, las agresiones sexuales, los abusos sexuales a niñas, el acoso sexual en todas sus manifestaciones, el tráfico o utilización de mujeres y niñas con finalidades de explotación sexual, prostitución y comercio sexual, la mutilación genital femenina, la violencia contra los derechos sexuales y reproductivos de las mujeres o cualquier otra situación o conducta que lesionara o fuera susceptible de lesionar la dignidad o integridad de la mujer. En cambio, se consideraba que, cuando se utilizaba el concepto de violencia doméstica, se hacía en un sentido más restringido, refiriéndose a las mujeres que sufren violencia ejercida contra ellas por parte de los que son o han sido sus cónyuges, o de los que están o han estado ligados con ellas por relaciones similares de afectividad, aunque no haya convivencia ${ }^{27}$.

24 Lousada Arochena, F. «Informe sobre el impacto de género en la elaboración normativa». La Ley, n. ${ }^{\circ}$ 6092/2004, pág. 3 .

25 Sobre el concepto de género utilizado por esta norma véase Molina Navarrete, C. «Las dimensiones sociolaborales de la 'lucha' contra 'la violencia de género'. A propósito de la Ley Orgánica 1/2004, de 28 de diciembre, de medidas de protección integral contra la violencia de género - BOE de 29 de diciembre-.» Revista de Trabajo y Seguridad Social. $C E F$, n. $^{\circ} 264 / 2005$, págs. 26 a 28. Según el autor, para esta norma legal, la violencia objeto de protección es cualquier acto de agresión, sea física o psíquica, que como manifestación de la situación desigual de poder existente, ejerza un hombre contra una mujer con la que mantiene o ha mantenido una relación afectiva de cierta duración, que implique o no convivencia. Véase también, entre otros, Menéndez Sebastián, P. y Velasco Portero, T. La incidencia de la violen cia de género en el contrato de trabajo. Ed. Cinca. Madrid, 2006, págs. 26 y siguientes, y Sempere Navarro, A. V. «La Ley Orgánica de Protección contra la violencia de género: una introducción para laboralistas». Aranzadi Social. Tomo $\mathrm{V} / 2005$, págs. 361 y siguientes.

26 Serrano Argüeso, M. «Las posibilidades de incorporación...», cit. pág. 69, nota 13, ya ponía de manifiesto en esta dirección, que en el momento en que entrara en vigor la norma que regulara la renta activa de inserción para el año 2005 se substituirían los términos de «violencia doméstica» por «violencia de género».

27 Ibíd. A partir de esta distinción, la autora considera que en el Derecho del Trabajo resulta confuso utilizar de esta 
Así mismo, también se consideró que la sustitución del término «violencia doméstica» por «violencia de género» podía tener un efecto restrictivo, por cuanto no coincide el colectivo de víctimas de violencia doméstica con el de víctimas de violencia de género, ya que el primero permite incorporar también a otras personas diferentes a las mujeres, que sufren violencia por el ejercicio de su pareja de un poder de dominación, mientras que el segundo no ${ }^{28}$.

Esta posible restricción, sin embargo, encontraba su razón última en que, a pesar de que la violencia doméstica puede afectar a otros sujetos integrantes de la unidad familiar, como por ejemplo a los hijos menores, las personas de edad avanzada, especialmente cuando se encuentran en situación de dependencia e, incluso, a los hombres, la contundencia de los datos estadísticos pone de manifiesto que la violencia contra las mujeres ocupa un lugar preferente — se calcula que el $91 \%$ de los supuestos-. Estos datos justificarían por sí mismos que la protección ante estas situaciones que dispensa la renta activa de inserción se limitara a las mujeres, dejando al margen de su ámbito de protección a otros colectivos especialmente vulnerables y también sometidos a poderes de dominación o de subordinación ${ }^{29}$.

Con toda probabilidad, para clarificar el alcance de la inclusión en la renta activa de inserción de este colectivo, el R. D. 1369/2006, de 24 de noviembre, ha vuelto a alterar el marco normativo de esta inclusión, estableciendo al efecto que «podrán ser beneficiarios del programa los trabajadores desempleados menores de 65 años que, a la fecha de solicitud de incorporación, reúnan los requisitos previstos en alguno de los párrafos siguientes: [... c) tener acreditada por la Administración competente la condición de víctima de violencia de género o doméstica, salvo cuando conviva con el agresor, y estar inscrita como demandante de empleo, siempre que se reúnan los requisitos exigidos en el apartado 1, excepto los recogidos en los párrafos $a$ ) y $b$ ). A los efectos de este programa, la violencia doméstica contemplada en el art. 173 del Código Penal queda limitada a la ejercida sobre el cónyuge o persona ligada por análoga relación de afectividad, o sobre los hijos o los padres».

A partir de este enunciado se constata que la inclusión de las víctimas de violencia de género o doméstica en el ámbito de aplicación de la renta activa de inserción, al igual que sucede en relación con el resto de colectivos protegidos, no se realiza de una forma genérica, sino que se exige el cumplimiento adicional de determinados requisitos:

forma los conceptos mencionados, ya que considera que con carácter general la violencia ejercida en el ámbito laboral contra la mujer es sin duda una manifestación de la violencia de género.

28 Molina Navarrete, C. y Vallecillo Gómez, M.R. «El “derecho a” y las “políticas de” de inserción...», cit. pág. 29.

29 Véase esta misma reflexión en relación con la Ley Orgánica 1/2004, de 28 de diciembre, en Molina Navarrete, C. «Las dimensiones sociolaborales...», op. cit., págs. 27 y 28. 
- Se tiene que tratar de una víctima de violencia de género o doméstica.

- No convivir con el agresor.

- Se ha de acreditar por la Administración competente la condición de víctima de violencia de género o doméstica.

- Se ha de estar inscrito como demandante de empleo.

- No se puede tener derecho a prestaciones o subsidios por desempleo o a la renta agraria.

- No pueden tenerse rentas, de cualquier naturaleza, superiores en cómputo mensual al 75\% del SMI, excluida la parte proporcional de dos pagas extraordinarias.

La primera cuestión que se plantea en relación con los posibles beneficiarios de la renta activa de inserción incluidos por esta vía, hace referencia una vez más a la terminología empleada por la normativa para identificar a este colectivo: «víctimas de violencia de género o doméstica». A tal efecto, para delimitar el colectivo de víctimas de violencia de género debe atenderse a lo previsto en el art. 1 de la Ley Orgánica 1/2004, de 28 de diciembre, de Medidas de Protección Integral contra la violencia de género, norma que, como su nombre indica, contiene una regulación general sobre esta materia. En virtud de esta norma, tendrá la consideración de víctima de violencia de género la mujer que sufre todo acto de violencia física y psicológica, incluidas las agresiones a la libertad sexual, las amenazas, las coacciones o la privación arbitraria de libertad, y que es ejercida sobre ésta por parte de quienes sean o hayan sido sus cónyuges, o de quienes estén o hayan estado ligados a ella por razones similares de afectividad, aun sin convivencia e independientemente de su estado civil.

Por su parte, para identificar el colectivo de víctimas de violencia doméstica debe acudirse a la delimitación específica de este colectivo que se lleva a cabo en el R. D. 1369/2006, de 24 de noviembre, en virtud del cual, a los meros efectos del programa de renta activa de inserción, la violencia doméstica contemplada en el art. 173 del Código Penal queda limitada a la ejercida sobre el cónyuge o persona ligada por análoga relación de afectividad o sobre los hijos o los padres.

En este punto, cabe recordar que el art. 173 del Código Penal, bajo el enunciado de trato degradante, tipifica entre otras conductas la siguiente: « 2 . El que habitualmente ejerza violencia física o psíquica sobre quien sea o haya sido su cónyuge, o sobre persona que esté o haya estado ligada a él por una análoga relación de afectividad aun sin convivencia, o sobre los descendientes, ascendientes o hermanos por naturaleza, adopción o afinidad, propios o del cónyuge o conviviente, o sobre los menores o incapaces que con él convivan o que se hallen sujetos a la potestad, tutela, curatela, acogimiento o guarda de hecho del cónyuge o conviviente, o sobre persona amparada en cualquier 
otra relación por la que se encuentre integrada en el núcleo de su convivencia familiar, así como sobre las personas que por su especial vulnerabilidad se encuentren sometidas a custodia o guarda en centros públicos o privados [..+]».

Ahora bien, como ya se ha avanzado, el art. 2.2 c) del Real Decreto 1369/2006, de 24 de noviembre, no recoge todas las situaciones de violencia doméstica contempladas en este precepto, sino únicamente se refiere «a la ejercida sobre el cónyuge o persona ligada por análoga relación de afectividad o sobre los hijos o los padres». En consecuencia, de la lectura conjunta de ambos preceptos puede concluirse que la referencia a las víctimas de violencia doméstica que contiene el art. 2.2 c) del R. D. 1369/2006, de 24 de noviembre, permitirá ampliar la posibilidad de acceder a la renta activa de inserción a los siguientes colectivos: $a$ ) al varón que sufra violencia ejercida por su cónyuge, excónyuge o persona ligada a él por análoga relación de afectividad, o por sus padres o sus hijos; y b) la mujer que sufra violencia ejercida por sus padres o por sus hijos.

En definitiva, la terminología introducida por el R. D. 1369/2006, de 24 de noviembre, que hace referencia tanto a la violencia de género como a la violencia doméstica, amplía sustancialmente el ámbito subjetivo y, en consecuencia, el ámbito de aplicación de la renta activa de inserción, puesto que, junto con los supuestos que ya venían incluidos por la referencia a la violencia de género - mujeres que sufren actos de violencia por parte de quienes sean o hayan sido sus cónyuges, o de quienes estén o hayan estado ligados a ella por razones similares de afectividad, aun sin convivencia e independientemente de su estado civil—, se incluyen ahora dos nuevos supuestos que hasta este momento quedaban excluidos del acceso a la renta activa de inserción por esta vía - hombres que sufren violencia ejercida por su cónyuge, excónyuge o persona ligada a él por análoga relación de afectividad, o por sus padres o sus hijos y mujeres que sufren violencia ejercida por sus padres o por sus hijos ${ }^{30}$ -

$\mathrm{El}$ art. 2.2 c) del R. D. 1369/2006 introduce un requisito adicional para que aquellas personas que tengan acreditada por la Administración competente la condición de víctima de violencia de género o doméstica puedan acceder a la renta activa de inserción, que consiste en no convivir con el agresor. A pesar de la restricción que puede suponer la adición de este requisito, dejando al margen de la protección dispensada por la renta activa de inserción a todas aquellas víctimas de violencia de género o doméstica que mantienen la convivencia con el agresor, con esta medida se persigue probablemente que tales víctimas rompan la convivencia con su agresor e inicien los procedimientos correspondientes poniendo fin de este modo a la situación en la que se encuentran ${ }^{31}$.

30 Vallecillo Gámez, M. R. y Molina Navarrete, C. «El régimen de estabilidad de la "renta activa de inserción” como subsidio no contributivo de la Seguridad Social: ¿realidad o pretención?. (Impacto jurídico y social del R. D. 1369/2006, de 24 de noviembre)». Revista de Trabajo y Seguridad Social. CEF, n. 3/2007, pág. 217, consideran acertado que se amplíe la protección a todas las víctimas de violencia familiar y no sólo a las mujeres víctimas de violencia de género. 31 El Consejo de Estado ha puesto de manifiesto que las modificaciones introducidas en este precepto están justificadas y no suscitan reparos. Véase Consejo de Estado: Dictamen al proyecto de Real Decreto..., op. cit. En esta dirección, 
Ahora bien, la normativa no exige únicamente que el solicitante de la renta activa de inserción sea una víctima de violencia de género o doméstica, sino que, además, exige que tenga acreditada por la Administración competente esta condición. Dado que la normativa no especifica quién y cómo se tendrá que extender dicha acreditación ${ }^{32}$, se deberá acudir a los mecanismos previstos en otras normas que también prevén derechos sociolaborales para las víctimas de violencia de género o doméstica. En este sentido, parece que la condición de víctima de violencia de género o doméstica se tendrá que certificar a través de la correspondiente orden de protección. Así se contempla de forma expresa en el art. 23 de la Ley Orgánica 1/2004, de 28 de diciembre, que bajo el enunciado de «acreditación de las situaciones de violencia de género ejercida sobre las trabajadoras» establece que «las situaciones de violencia que dan lugar al reconocimiento de los derechos regulados en este capítulo se acreditarán con la orden de protección a favor de la víctima».

A tal efecto, el art. 544 ( 8 de la Ley de Enjuiciamiento Criminal prevé en relación con la orden de protección para las víctimas de violencia doméstica que «la orden de protección será notificada a las partes y comunicada por el juez inmediatamente, mediante testimonio íntegro, a la víctima y a las Administraciones Públicas competentes para la adopción de medidas de protección, sean estas de seguridad o de asistencia social, jurídica, sanitaria, psicológica o de cualquier otra naturaleza». Con esta finalidad, el mencionado precepto prevé el establecimiento de un sistema integral de coordinación administrativa que garantice la agilidad de estas comunicaciones. Únicamente de forma excepcional se prevé la posibilidad de que la condición de víctima se acredite mediante un informe del Ministerio Fiscal que ponga de manifiesto la existencia de indicios de que la solicitante es víctima de violencia de género, hasta que no se dicte la correspondiente orden de protección (art. 23 de Ley Orgánica 1/2004, de 28 de

\footnotetext{
Monereo Pérez, J. L. y Triguero Martínez, L. A. La victima de violencia de género y su modelo de protección social. Ed. Tirant lo Blanch. Valencia, 2009, pág. 149, consideran que el requisito adicional de la no convivencia de la víctima con el agresor puede considerarse acertada por dos motivos: en primer lugar, porque se está imponiendo a la víctima una protección como resultado de su no convivencia con el agresor; y, en segundo lugar, porque ante la ausencia de este requisito, en algunas ocasiones se podría originar una pérdida de efectividad de esta medida y acogimiento al programa de forma indebida, ya que la víctima conviviría con el agresor y no se la ayudaría realmente a salir de la situación de exclusión socio-profesional que pretende la renta activa de inserción. Por su parte, Vallecillo Gámez, M. R. y Molina Navarrete, C. «El régimen de estabilidad...», op. cit. pág. 217, consideran que, si bien la exclusión parece razonable, porque fomenta la salida de la víctima del entorno hostil y su vida autónoma, y es coherente con la regulación específica prevista para las víctimas de violencia de género, su aplicación rígida puede plantear algún problema de desprotección.

32 Leonés Salido, J. M. «Algunas sombras del Real Decreto-ley de medidas urgentes para la reforma del desempleo». La Ley, n. ${ }^{\circ}$ 5561/2002, en relación al programa para el año 2002 consideraba que se trataba de una norma en blanco, a partir de la cual se aventuraba la posibilidad que se exigiera una sentencia firme condenatoria o que se considerara suficiente con la aportación de la simple denuncia. Ante las dudas que plantea este precepto, Esteban Legarreta, R. «Fomento del empleo e intermediación de los beneficiarios de la renta activa de inserción: un estudio de su evolución». Temas Laborales, n. ${ }^{\circ} 74 / 2004$, pág. 49 , considera que debe ser determinante para constatar tal situación desde una visión de conjunto la actuación de los Servicios Sociales.
} 
diciembre). En cualquier caso, no será necesaria sentencia condenatoria para poder acreditar la condición de víctima de violencia de género o doméstica ${ }^{33}$.

Esta exigencia de acreditación de la condición de víctima de violencia de género o doméstica por parte de la Administración competente es mayoritariamente aceptada por la doctrina, puesto que, al tratarse de ayudas económicas, podrían, en el supuesto de que no se exigiera de forma estricta la acreditación de esta situación, darse situaciones de picaresca y de fraude, lo que en última instancia iría en detrimento de las personas que verdaderamente sufren la violencia de género o doméstica ${ }^{34}$. Sin embargo, también se ha mantenido que, en ocasiones, puede resultar excesivamente burocrática, así como molesta, la necesidad de acreditar la situación de víctima de violencia de género o doméstica, en tanto en cuanto esta situación ya es por sí sola suficientemente penosa, como para que además se etiquete a la víctima. Así mismo, puede retardar el acceso de la víctima a las correspondientes ayudas económicas y de inserción previstas por la renta activa de inserción.

El resto de requisitos exigidos para que el colectivo de víctimas de violencia de género o doméstica pueda acceder a la renta activa de inserción son comunes al resto de colectivos beneficiarios de la misma y, por tanto, responden a las mismas circunstancias que se hacen exigibles para los otros colectivos. En concreto, se exige estar inscrito como demandante de empleo; no tener derecho a las prestaciones o subsidios por desempleo o a la renta agraria, y no tener rentas, de cualquier naturaleza, superiores en cómputo anual al 75\% del SMI, excluida la parte proporcional de dos pagas extraordinarias. Es, justamente, la exigencia de estos requisitos la que nos permite constatar el claro carácter asistencial y subsidiario de esta prestación.

Ninguna cuestión plantea la exigencia de estos requisitos, si bien podría haberse flexibilizado el requisito del nivel de rentas en aquellos supuestos en que la víctima se integre en el hogar de padres y/o hermanos; no en vano, una aplicación rígida de las reglas de cómputo de rentas llevaría a computar en un todo los ingresos de los familiares hasta segundo grado con los que se conviva de modo circunstancial, excluyendo a la víctima del acceso a la renta activa de inserción, lo cual es contradictorio con los beneficios que pueden derivarse en estos supuestos del hecho de dotar de una mayor autonomía económica a los beneficiarios y, sobre todo, de asegurar el acompañamiento en la búsqueda de empleo que implica la inclusión en la renta activa de inserción ${ }^{35}$.

Por el contrario, se eliminan algunos requisitos exigidos a otros colectivos, en particular el de ser mayor de 45 años y estar inscrito como demandante de empleo ininte-

33 Rabanal Carbajo, P. «Disposiciones Adicionales». Documentación Laboral, n. ${ }^{\circ}$ 67/2003, pág. 175.

34 Serrano Argüeso, M. «Las posibilidades de incorporación...», op. cit., pág. 68.

35 Esteban Legarreta, R. La renta activa de inserción. Ed. Tirant lo Blanch. Valencia, 2006, pág. 44. El autor considera más adecuado en estos supuestos computar únicamente los ingresos del solicitante y los de los familiares convivientes con anterioridad a la salida del hogar familiar y que continúen conviviendo con aquel. 
rrumpidamente durante 12 o más meses ${ }^{36}$. La supresión de estos dos requisitos se encuentra en consonancia con las especiales características del colectivo al cual va dirigida esta prestación. En concreto, resulta plenamente lógica la supresión de la exigencia de la edad, en tanto que nada tiene que ver la misma con la condición de víctima de violencia de género o doméstica y, por tanto, con las necesidades económicas y las dificultades para encontrar trabajo de este colectivo. Mantener este requisito supondría añadir un plus de dificultad para el acceso al mercado de trabajo. Así mismo, resulta totalmente razonable la supresión de la exigencia de un período mínimo de inscripción como demandante de empleo, ya que, en los supuestos de violencia de género o doméstica, la protección ha de tener un carácter de urgencia, no pudiéndose posponer durante un año la protección dispensada por la renta activa de inserción.

En cuanto al conjunto de requisitos de carácter objetivo que se exigen a las víctimas de violencia de género o doméstica para acceder a la renta activa de inserción, básicamente la suscripción de un compromiso de actividad que obliga al beneficiario a participar en diversas actividades de inserción (art. 3 R. D. 1369/2006), no existen diferencias en la configuración de dicha obligación respecto al resto de colectivos que pueden acceder a la citada prestación, salvo una pequeña excepción prevista en el art. 231.2 TRLGSS, precepto al que se remite el art. 3 R. D. 1369/2006 para concretar el alcance del compromiso de actividad, el cual señala que el servicio público de empleo a la hora de valorar el cumplimiento de las obligaciones derivadas de dicho compromiso de actividad (buscar activamente un empleo, aceptar una colocación adecuada, etc.) tendrá en cuenta la condición de víctima de violencia de género a efectos de «atemperar», en caso necesario, el cumplimiento de las obligaciones que se deriven del compromiso suscrito.

Por último, y en relación al requisito temporal previsto en el art. 2.4 del R. D. $1369 / 2006$, se vuelve a realizar una nueva excepción a favor de este colectivo, al no exigirse el no haber sido beneficiario de la renta activa de inserción en los 365 días naturales anteriores a la fecha de solicitud del derecho a la admisión al programa ${ }^{37}$.

Esta excepción se ha venido recogiendo hasta la fecha en los diferentes programas de renta activa de inserción desde el año 2002, justamente desde la incorporación de dos nuevos colectivos de beneficiarios de la renta activa de inserción como son las víctimas de violencia doméstica (hoy, de violencia de género y doméstica) y las personas que acreditaran la condición de minusválidas. Esta previsión, por tanto, suponía la adaptación del requisito temporal a las especiales características de estos dos colec-

36 Véase art. 2.2. R. D. 1369/2006, de 24 de noviembre.

37 Con anterioridad al R. D. 1369/2006, el requisito temporal se formulaba no en relación al año anterior, sino, primero, en relación a la condición de beneficiario anteriormente de la renta activa de inserción, y posteriormente en relación al programa de renta activa del año anterior. La nueva formulación es coherente con la nueva concepción de la renta activa de inserción, que ya no se articula a través de programas temporales de carácter anual, sino que se articula con carácter permanente estableciendo una garantía de continuidad en su aplicación como un derecho más. 
tivos, las cuales justifican que estos colectivos puedan acceder nuevamente de forma ininterrumpida a esta prestación, con el fin de que puedan satisfacer el objetivo de la inserción sociolaboral de los mismos.

De acuerdo con lo expuesto hasta ahora, cabe valorar positivamente la inclusión del colectivo de las víctimas de violencia de género o doméstica en el ámbito subjetivo de la renta activa de inserción. No obstante, es necesario poner de manifiesto que en este colectivo confluyen circunstancias especiales y diferenciadas del resto de colectivos con los que comparte la protección dispensada por esta prestación, lo que lleva a que su tratamiento a la hora de acceder a la renta activa de inserción también sea diferenciado. Estas circunstancias provocan que, en numerosas ocasiones, esta prestación se aproxime más que en ningún otro supuesto al concepto de renta mínima de inserción y, por tanto, se aleje todavía más de su consideración como un tercer nivel de protección por desempleo. Por tanto, en estos supuestos, el objetivo de la reinserción laboral y protección frente al desempleo característico de la renta activa de inserción se ve complementado y, en muchas ocasiones, incluso superado y/o substituido, por una finalidad de inserción social. No en vano, en numerosas ocasiones la inserción laboral de este colectivo necesita, más que ningún otro, de una previa inserción social del mismo ${ }^{38}$.

Reforzando esta idea encontramos que diversas rentas mínimas de inserción autonómicas, entre las que se incluye la renta mínima de inserción de Cataluña, también contemplan la posibilidad de acceder a las mismas a las víctimas de violencia de género o doméstica, incluso previendo para ellas un tratamiento «privilegiado». Así, por ejemplo, en el caso de la renta mínima de inserción de Cataluña, prevé entre diferentes excepciones al requisito exigido de residencia, el supuesto de mujeres que hayan tenido que marchar de su lugar de residencia y hayan llegado a Cataluña para evitar malos tratos a ellas o a sus hijos, y se encuentren en situación de pobreza severa. En la misma dirección, el art. 46 de la Ley 5/2008, de 24 de abril, del derecho de las mujeres a erradicar la violencia machista, prevé que, para favorecer la autonomía de las mujeres que se encuentren en situación de violencia machista, en relación con el requisito de carecer de rentas que exige la renta mínima de inserción catalana, se tenga exclusivamente en cuenta los ingresos y las rentas individuales de cada mujer, siempre que se cumplan los restantes requisitos exigidos por la normativa reguladora de la renta mínima de inserción. Estas medidas ponen de manifiesto la importancia que las rentas mínimas de inserción deben jugar a la hora de proteger a este colectivo, complementando de este modo otras medidas previstas por el ordenamiento jurídico.

38 En términos parecidos se manifiesta Molina Navarrete, C. «Las “rentas activas de inserción”: un viaje...».op. cit., pág. 450 . 


\subsection{Contenido prestacional de la renta activa de inserción prevista para las mujeres víctimas de violencia de género o doméstica}

El doble objetivo que persigue la renta activa de inserción, por un lado remover o, en su caso, mitigar las necesidades económicas de los beneficiarios de la misma, y por otro la inserción de los mismos en el mercado de trabajo, ha llevado a que el contenido prestacional de la renta activa de inserción se haya configurado de forma dual ${ }^{39}$, a través de la percepción de la renta activa de inserción y de la configuración de un conjunto de acciones de inserción que se articulan a través del compromiso de actividad, y más recientemente también con las ayudas para incentivar el trabajo ${ }^{40}$. En este punto cabe señalar que no se han previsto por el legislador medidas excepcionales o diferenciadoras para las víctimas de violencia de género o doméstica y, por tanto, su regulación es igual que para el resto de colectivos beneficiarios de la renta activa de inserción (cuantía de la prestación, duración, concreción de las acciones de inserción laboral, etc. ${ }^{41}$ ).

La combinación de una prestación económica y de acciones de inserción sociolaboral que definen a la renta activa de inserción garantiza que la misma sea una medida adecuada a los fines pretendidos de inserción y de protección de este colectivo. De una parte, la ayuda económica proporcionada, por insuficiente que sea, va a resultar totalmente necesaria al objeto de proceder a una ruptura con la dependencia que la víctima presenta respecto de los cónyuges maltratadores; $y$, por otra parte, el programa de inserción puede ser muy útil si estas personas abandonaron hace tiempo el mercado de trabajo ${ }^{42}$.

Ahora bien, junto con el contenido tradicional de la renta activa de inserción, que conjuga políticas activas y pasivas, se han incorporado últimamente otras ayudas económicas que, probablemente, no responden únicamente a estas finalidades, sino que tienen un carácter más bien dirigido a la protección de determinados colectivos, dada la situación excepcional en la que se encuentran. Nos referimos a la previsión de ayudas

39 Para un estudio del contenido dual de la renta activa de inserción, véase, entre otros, Moreno Gené, J. y Romero Burillo, A. M. «El carácter dual del contenido prestacional de la renta activa de inserción. A propósito del programa para el año 2005». Aranzadi Social, n. ${ }^{\circ}$ 14/2005.

40 Las ayudas para incentivar el trabajo se incorporaron por primera vez en el R. D. 205/2005, concretamente el art. 6 preveía que el beneficiario de la renta activa de inserción percibiera la prestación económica en su totalidad o en un $50 \%$; esta cuantía le era retraída del salario legal o convencional, lo que suponía un beneficio para el empresario, y en consecuencia un incentivo para la contratación de los beneficiarios de la renta activa de inserción. El art. 6 del R. D. 1369/2006 ha mantenido las ayudas puestas en marcha para el año 2005, aunque se configuran de una forma diferente, ya que se establece que los trabajadores admitidos en el programa que realicen un trabajo por cuenta propia o ajena a tiempo completo percibirán una ayuda equivalente al $25 \%$ de la cuantía de la renta durante un máximo de 180 días a partir del primer día de trabajo tras la solicitud de admisión al programa.

41 Para un estudio del contenido prestacional de la actual renta activa de inserción véase Moreno Gené, J. y Romero Burillo, A. M. El nuevo régimen jurídico de la renta activa de inserción. (A propósito del Real Decreto 1369/2006, de 24 de noviembre). Ed. Aranzadi, Cizur Menor, 2007.

42 Monereo Pérez, J. L. y Triguero Martínez, L. A. La víctima de violencia de género..., op. cit., pág. 149. 
dirigidas al cambio de residencia de víctimas de violencia de género, las cuales probablemente podrían haber encontrado mejor acomodo en la Ley Orgánica 1/2004, de 28 de diciembre, de medidas de protección integral contra la violencia de género, o en su normativa de desarrollo ${ }^{43}$, y los incentivos a la contratación que periódicamente se recogen en el correspondiente programa de fomento del empleo. Veamos brevemente en qué consisten cada una de estas medidas.

a) La ayuda especifica para las víctimas de violencia de género o doméstica.

El programa de renta activa de inserción para el año 2002, al tiempo que previó la incorporación de las víctimas de violencia doméstica - actualmente de violencia de género o doméstica - incorporó una ayuda suplementaria dirigida a las mismas. En este sentido, la norma 8.2 d) de la Disposición Adicional primera de la Ley 45/2002 previó que las víctimas de violencia doméstica que se vieran obligadas y acreditasen cambio de residencia podrían percibir en un pago único una ayuda suplementaria de 3 meses de renta activa de inserción, sin que se redujera la duración de la citada renta y sin aplicación, en su caso, del período de espera de 3 meses. Dadas las cuestiones prácticas que se derivaron de esta previsión ${ }^{44}$, los programas posteriores fueron incorporando precisiones a esta ayuda por cambio de residencia de víctimas de violencia de género o doméstica hasta llegar a la actual regulación.

El R. D. 1369/2006 sigue manteniendo estas ayudas para el cambio de residencia; sin embargo, como indica el Preámbulo de dicha norma, estas ayudas se incorporarán en la normativa reguladora de la renta activa de inserción «hasta tanto se establezca una financiación y consignación presupuestaria de esta ayuda al margen del sistema de protección por desempleo», de tal modo que es de prever que, en un plazo razonable de tiempo, estas ayudas, de carácter más bien social que no dirigidas específicamente a la reinserción profesional, abandonen la órbita de la renta activa de inserción para ubicarse en el conjunto de ayudas sociales previstas para las víctimas de violencia de género o doméstica ${ }^{45}$. Este carácter coyuntural con el que se incluyen estas ayudas en el R. D. 1369/2006 conlleva que las mismas no se incorporen en el cuerpo normativo de esta norma, sino en la Disposición Transitoria Primera bajo la rúbrica de «ayuda para cambio de residencia de víctimas de violencia de género o doméstica».

43 La misma opinión en Luján Alcaraz, J. «El programa de renta activa de inserción para 2005». Aranzadi Social, $\mathrm{n} .^{\circ} 2 / 2005$. El autor considera que se trata de «puras ayudas sociales no vinculadas directamente con el objetivo de reinserción profesional».

44 Rabanal Carbajo, P. «Disposiciones...», op. cit., págs. 183 y 184.

$45 \mathrm{La}$ inclusión de estas ayudas en la renta activa de inserción ha sido objeto de crítica por parte de los interlocutores sociales en los Informes elaborados con motivo del proyecto de renta activa de inserción. Véase Consejo de Estado: Dictamen del proyecto de Real Decreto..., op. cit. 
De la redacción actual de esta ayuda para el cambio de residencia de víctimas de violencia de género o doméstica, se pueden extraer los siguientes elementos:

- En primer lugar, para ser beneficiario de esta ayuda deben reunirse los siguientes requisitos: a) tratarse de una víctima de violencia de género o doméstica, en los términos definidos en el art. 2.2 c) del R. D. 1369/2006; b) haberse visto obligada a cambiar de residencia y acreditar esta circunstancia; $c$ ) que el cambio de residencia haya tenido lugar en los 12 meses anteriores a la solicitud de admisión al programa, o durante su permanencia. Se establece, por tanto, un margen relativamente amplio para poder acceder a esta ayuda complementaria, en tanto en cuanto se podrá solicitar esta ayuda siempre que el cambio de residencia se haya producido como máximo con 12 meses de antelación, límite temporal que, por otra parte, no se introdujo hasta el programa para el año 2003. Así mismo, cabe destacar que también se podrá acceder a esta ayuda suplementaria con posterioridad al acceso como beneficiario de la renta activa de inserción, en tanto en cuanto se mantenga la permanencia de éste en el mismo.

- En segundo lugar, por lo que respecta al contenido de esta ayuda, consiste en el pago de un único suplemento económico equivalente a 3 meses de renta activa de inserción ${ }^{46}$. Esta cantidad, si bien puede permitir atender a los primeros gastos derivados de este cambio de residencia, difícilmente será suficiente para sufragar los gastos posteriores derivados del mismo. En todo caso, esta ayuda debe ser considerada en el marco de la protección integral dispensada por la Ley Orgánica 1/2004, de 28 de diciembre, de medidas de protección integral contra la violencia de género. A tal efecto, dicha norma prevé en su art. 27 una ayuda social de carácter económico de pago único supeditada al cumplimiento de dos requisitos: por un lado, la carencia de rentas mensuales superiores al $75 \%$ del SMI, excluidas las partes proporcionales de las pagas extraordinarias; y, por otro, la presunción de que, debido a la edad, la mujer víctima de la violencia de género presente una carencia de preparación general o especializada y circunstancias sociales difíciles que le complican el encuentro de un empleo, motivos que impiden su participación en programas de empleo establecidos para la inserción profesional. El importe de esta ayuda consiste en una prestación de tracto único equivalente al importe de seis meses de subsidio por desempleo, si bien aumentado en los casos de minusvalías o de responsabilidades familiares.

46 Rabanal Carbajo, P. «Disposiciones...», op. cit., pág. 184, a pesar de la literalidad de la norma, no considera que se pueda sostener que esta ayuda suplementaria haya de percibirse de una sola vez y por la cuantía de 3 meses de la renta, porque la citada ayuda no se recibe para facilitar el cambio, sino precisamente por ya haberse producido éste. En todo caso, el autor considera que no resulta atrevida la idea de que se reciba esta cantidad de una sola vez. 
- En tercer lugar, en relación con el momento en que se puede percibir esta ayuda, la Disposición Transitoria Primera del R. D. 1369/2006 prevé que la misma se podrá recibir a partir del día siguiente a aquél en que se solicite. La celeridad en la concesión de estas ayudas responde obviamente a la urgencia de la situación contemplada en estos supuestos, donde la necesidad urgente de cambiar de residencia de la víctima de violencia de género o doméstica hace imprescindible que obtenga los recursos económicos necesarios para poder llevar a la práctica este cambio de residencia ${ }^{47}$. Por este motivo, los programas de renta activa de inserción anteriores, pese a prever un período de espera -1 o 3 meses - para acceder a la renta activa de inserción, no exigían que transcurriera dicho plazo para poder acceder en estos supuestos a las ayudas para cambio de residencia.

- En cuarto lugar, aunque la Disposición Transitoria Primera del R. D. 1369/2006 ha suprimido la previsión contenida en anteriores programas de renta activa de inserción, según la cual la percepción de la ayuda no minoraría la duración de la renta activa de inserción - 11 meses a partir del año 2005-, del tenor de esta Disposición, que califica a esta ayuda como «una ayuda suplementaria», se sigue desprendiendo que la percepción de la misma no supondrá una reducción de la duración de la renta activa de inserción, de manera que la beneficiaria seguirá teniendo derecho a la percepción de esta prestación durante un período de 11 meses. En consecuencia, en estos supuestos los beneficiarios de la renta activa de inserción pueden llegar a percibir un máximo de 14 mensualidades de renta ( 3 por cambio de residencia y 11 propiamente de renta activa de inserción).

- En quinto lugar, la ayuda para el cambio de residencia de víctimas de violencia de género o doméstica se podrá percibir únicamente una vez por cada derecho a la admisión al programa de renta activa de inserción; en consecuencia, si bien únicamente se podrá solicitar y obtener esta ayuda una vez en cada derecho de admisión al programa, podrá accederse a la misma tantas veces como se acceda y se sea beneficiario de la renta activa de inserción, de conformidad con lo previsto en el art. 4 del R. D. 1369/2006.

- Finalmente, el apartado segundo de la Disposición Transitoria Primera del R. D. $1369 / 2006$ se remite a lo previsto en los arts. $11.6,13.1$ y 15.2 para la tramitación, gestión y financiación de la renta activa de inserción, y para regular el régimen jurídico de reconocimiento, abono y financiación de las ayudas para cambio de residencia de víctimas de violencia de género o doméstica, todo ello

47 Rabanal Carbajo, P. «Disposiciones...», op. cit., pág. 184, considera sin embargo que esta ayuda no se recibe para facilitar el cambio, sino precisamente porque éste ya se ha producido, lo que se desprende de la exigencia que contempla la norma de que los beneficiarios «acrediten cambio de su residencia», y no la necesidad de tener que cambiar de residencia, de lo que se deduce que el citado cambio de residencia se trata de un hecho consumado. 
con la finalidad de garantizar la eficacia en la gestión de estas ayudas y para asegurar su inmediata puesta a disposición a las víctimas de violencia de género o doméstica.

\section{b) Las bonificaciones a la contratación}

Otra medida que tradicionalmente se ha vinculado a la inserción laboral de los beneficiarios de la renta activa de inserción ha sido la previsión de bonificaciones para la contratación de dichos beneficiarios. En este punto, el art. 22 de la Ley Orgánica $1 / 2004$ de protección contra la violencia de género establece que «en el marco del plan de empleo del Reino de España, se incluirá un programa de acción específico para las víctimas de violencia de género inscritas como demandantes de empleo». Ahora bien, a diferencia del resto de acciones de inserción laboral previstas, estas bonificaciones no se han recogido en la norma reguladora del correspondiente programa de renta activa de inserción, sino en los diversos y sucesivos programas para el fomento del empleo que se aprueban periódicamente.

De esta manera, al margen del primer programa para el año 2000, que no vino acompañado de previsión de bonificaciones referidas específicamente a los beneficiarios de la renta activa de inserción, ya el programa para el año 2001 vino acompañado de dichas bonificaciones, las cuales se han mantenido de forma casi inalterable hasta el programa de fomento de la contratación previsto para el año 2006.

En la dirección señalada, y de conformidad con la Ley 43/2006, de 29 de diciembre, para la mejora del crecimiento y del empleo, la contratación de desempleados admitidos al programa que contempla la ayuda específica denominada renta activa de inserción da acceso a una serie de bonificaciones para el empresario. En concreto, el art. 2.4 de esta norma contempla de forma expresa que los empleadores que contraten indefinidamente a personas que tengan la condición acreditada de víctimas de violencia de género en los términos de la Ley Orgánica 1/2004, o de víctima de violencia doméstica, sin que sea necesaria la condición de estar en situación de desempleo, tendrán derecho, desde la fecha de celebración del contrato, a una bonificación mensual de la cuota empresarial a la Seguridad Social o, en su caso, por su equivalente diario, por trabajador contratado de 70,83 euros/mes (850 euros/año) durante 4 años. Así mismo, en el caso de que se celebren contratos temporales con estas personas, se tendrá derecho a una bonificación mensual de la cuota empresarial a la Seguridad Social o, en su caso, por su equivalente diario, por trabajador contratado de 50 euros $/ \mathrm{mes}$ (600 euros/año), durante toda la vigencia del contrato. 